\title{
Lactobionic Acid Produced by Zymomonas mobilis: Alternative to Prepare Targeted Nanoparticles
}

\author{
Ticiana Alexandra Valle ${ }^{1}$, Ângelo Adolfo Ruzza ${ }^{3}$, Marco Fabio Mastroeni ${ }^{1}$, Eloane Malvessi ${ }^{2}$, Maurício Moura da Silveira ${ }^{2}$, Ozair de Souza ${ }^{4}$ \\ and Gilmar Sidnei Erzinger ${ }^{1 *}$
}

${ }^{1}$ Department of Health and Environment, University of Joinville Region, SC, Brazil

${ }^{2}$ Biotechnology Institute, University of Caxias do Sul (INBio/UCS), RS, Brazil

${ }^{3}$ Department of Chemistry University Federal of Santa Catarina, SC, Brazil

${ }^{4}$ Department of MSc in Process Engineering, University of Joinville Region, SC, Brazil

\begin{abstract}
The bacterium Zymomonas mobilis has the ability to produce several organic acids from mixtures of fructose and different aldoses as an alternative to glucose. One of these organic acids, lactobionic acid, is produced from the oxidation of lactose and is produced in equimolar amounts with sorbitol, a product of fructose reduction. Sorbitol is widely used in the food and pharmaceutical industry, while lactobionic acid has important applications in medicine and cosmetics. It has been reported in the literature that lactobionic acid has the potential for drug vectorization, particularly for anti-tumor drugs. The objective of this work is to show that lactobionic acid produced by Zymomonas mobilis can be used for targeted delivery of chemotherapeutic agents. Using analytical techniques such as HPLC, NMR and polarimetry, we showed that lactobionic acid produced in Zymomonas mobilis is of high purity (100\%) when compared to the $97 \%$ pure lactobionic acid salt from Sigma ${ }^{\circledR}$, which was used as a reference. In addition, the lactobionic acid made from Zymomonas was free of any contaminants or racemic isomers and had an open chain, suggesting its suitability for targeted delivery of nanoparticle drugs.
\end{abstract}

Keywords: Lactobionic acid; Zymomonas mobilis; Nanoparticles; Drug delivery

\section{Introduction}

Drug vectorization is a therapeutic strategy where drug release is controlled at specific sites of action (specific cells, tissues or organs), thereby increasing the therapeutic efficacy of the drug and reducing systemic toxicity $[1,2]$.

This technique has major advantages over non-targeted delivery because it can simplify the administration process for a drug, reduce the cost of therapy and allow for higher concentrations of the drug to be used in the desired location without causing toxic effects elsewhere [3-12].

The combination of targeted drug delivery and new techniques in nanotechnology holds great promise for the field of pharmaceuticals. One of the main compounds currently being considered for targeted drug delivery is the lactobionic acid due to its strong interaction with hepatocytes [5-12].

In the journal Biomaterials, Kamruzzaman Selim et al. reported on the coating of magnetic nanoparticles with lactobionic acid as a livertargeting contrast agent [7]. Lactobionic acid is a type of sugar that binds to a receptor on the surface of the liver cells. The investigators found that when they added these nanoparticles to cultured liver cells, the nanoparticles accumulated inside the cells. In contrast, liver cells took up very few nanoparticles that were coated with a related sugar known as maltotrionic acid, indicating that lactobionic acid was acting as the hepatocyte-targeting agent.

There are several lactobionic acid suppliers worldwide and most lactobionic acid is sufficiently pure for use in chemical and pharmaceutical synthesis. In 2009, the Vale group analyzed 'highpurity' lactobionic acid from different companies with the goal of targeted drug delivery on a commercial scale [13]. Samples of the lactobionic acid salt from Sigma ${ }^{\circledR}$, which is the form used in nearly all targeted drug delivery studies [5-12], showed a deviation of higher than $30 \%$ in the amount of absorbed polarized light.

Studies developed at the Biotechnology Institute (INBio) at the University of Caxias do Sul (UCS) indicated that Zymomonas mobilis produced high quality lactobionic acid and sorbitol. In 2007, the Biotechnology Institute (INBio) in Brazil submitted a biotechnology patent for the production of lactobionic acid in Zymomonas mobilis at INPI [14]. The gram-negative bacterium Zymomonas mobilis produces lactobionic acid from lactose and sorbitol from fructose in a biotransformation catalyzed by the periplasmic enzymes glucosefructose oxidoreductase (GFOR) and $\beta$-glucono-lactonase (GL), respectively [15-19].

The aim of this study was to determine if the lactobionic acid that was produced by the UCS could be processed to obtain a product free of toxic waste following organic catalysis and with a purity similar to lactobionic acid from Sigma ${ }^{\circledR}$ and whether this product may be used as an alternative agent for drug vectorization.

\section{Material and Methods}

\section{Lactobionic acid samples}

Lactobionic acid salt from Sigma ${ }^{\circledR}$, with a purity of $97 \%(086 \mathrm{k} 0887$,

*Corresponding author: Gilmar Sidnei Erzinger, Department of Health and Environment, University of Joinville Region, SC, Brazil, E-mail: gilmar.sidnei@univille.br

Received February 28, 2013; Accepted March 18, 2013; Published March 22 2013

Citation: Valle TA, Ruzza ÂA, Mastroeni MF, Malvessi E, da Silveira MM, et al (2013) Lactobionic Acid Produced by Zymomonas mobilis: Alternative to Prepare Targeted Nanoparticles. Pharmaceut Anal Acta 4: 220. doi:10.4172/21532435.1000220

Copyright: ( 2013 Valle TA, et al. This is an open-access article distributed under the terms of the Creative Commons Attribution License, which permits unrestricted use, distribution, and reproduction in any medium, provided the original author and source are credited. 
reference number L 2398), was used as a control for the chemical characterization of the lactobionic acid produced by Zymomonas mobilis ATCC 29191 in a process that was developed by the Biotechnology Institute, University of Caxias do Sul, Brazil [14].

\section{High Performance Liquid Chromatography (HPLC)}

HPLC analysis of lactobionic acid samples was conducted using a Merck-Hitachi model D-7000 IF instrument with a refractive index detector (RI-71) made by Merck-Hitachi and from the Laboratory of Instrumental Analysis of UNIVILLE. The column was from Transgenomic with a stationary phase of polystyrene with hydrogen (protons) functional groups (model ICE-ION-300), and it was enclosed in a Merck-Hitachi oven (model L7100) set to $700^{\circ} \mathrm{C}$. The eluent was $8.5 \mathrm{mM}$ sulfuric acid, and the injected sample volume was $20 \mu \mathrm{l}$ [18].

\section{Polarimetry - optical-rotatory dispersion}

For polarimetric analysis of lactobionic acid samples, we used a polarimeter (Schmidt \& Haensch, model Palatronic E), and the results were obtained using the following formula for specific rotation, which is countersigned by the Merck Index [20]:

$$
\alpha=\frac{\alpha \text { obs }}{\mathrm{c}(\mathrm{g} / \mathrm{mL}) \cdot \mathrm{c}(\mathrm{dm})}
$$

The following variables were used: $\mathrm{C}$ is the concentration in $\mathrm{g} \mathrm{mL}^{-1}$, $c$ is the length of the polarimeter in decimeters, $\alpha$ obs is the absorbance reading and $\alpha$ is the optical-rotatory dispersion at $20^{\circ} \mathrm{C}$.

\section{NMR Spectroscopy}

${ }^{13} \mathrm{C}$-NMR spectra were obtained using a Varian NMR spectrometer (AS-400, $400 \mathrm{MHz}$ ) with $\mathrm{D}_{2} \mathrm{O}$ (deuterium oxide) as the solvent for all samples. Specification of equipment and internal cooling were performed using helium and liquid nitrogen. The chemical shifts $(\delta)$ were expressed in parts per million compared to the solvent. A few drops of deuterated acetone $\left(\mathrm{C}_{3} \mathrm{D}_{6} \mathrm{O}\right)$ were used to obtain a calibration point for the chemical shifts with respect to the ${ }^{13} \mathrm{C}$ signal. The signal for deuterated acetone varied between 29.68 to $29.80 \mathrm{ppm}$. Determinations of the signs were conducted using a computer system connected to MRI equipment.

\section{Statistics}

The data were expressed as the mean \pm standard deviation. Kolmogorov-Smirnov tests were performed to determine the significance of differences between the control and experimental samples of lactobionic acid. All reported $p$-values were based on twosided tests and compared to a significance level of 5\%. SPSS 18.0 (SPSS Inc., Texas, USA) software was used for all the statistical calculations.

\section{Results and Discussion}

\section{Determination of purity by HPLC analysis}

To determine the quality of the lactobionic acid that was produced by Zymomonas mobilis, HPLC analysis was performed with eight samples prepared in duplicate for each salt $(\% \mathrm{w} / \mathrm{v})$, the real and theoretical purity values were calculated. As described in the Material and Methods section, the lactobionic acid salt from Sigma ${ }^{\circledR}$ had a purity of $97 \%$. The results from the HPLC analysis of the lactobionic acid samples are summarized in Table 1.

The purpose of conducting these tests was to analyze different samples on a mass basis because acquiring a primary standard with
$100 \%$ purity can be difficult. These results demonstrate that the lactobionic acid salt from Sigma ${ }^{\circledR}$ had a $1 \%$ difference between the theoretical and real purity values; however, this difference was not significant $(p=0.964)$. The lactobionic acid produced by Zymomonas mobilis at UCS had an $11 \%$ difference between the theoretical and real purity values and also showed no statistical significance $(p=0.088)$. This finding may be justified because the calibration curve was made with a sample that had only $97 \%$ purity. An analysis of the significance between the samples suggested that these salts had no contaminants or racemic isomers.

The calibration curve shown in Figure 1 demonstrates that at low concentrations the chromatograms showed a second peak of lower intensity in addition to the peak for lactobionic acid. This peak was not observed at concentrations higher than $10 \mathrm{mg} / \mathrm{L}$. Pedruzzi et al. explained this phenomenon by suggesting that sugars at low concentrations may contain racemic mixtures or optical isomers [18].

\section{Optical rotatory relationships}

A number of empirical relationships have been derived from the optical rotation of acid, lactones, salt and other compounds. These relationships have been important for establishing the configuration of a new acid, in particular that of its epimers. They have also been useful for establishing the ring size of lactone [18].

This test compared the optical rotation of lactobionic acid samples from Sigma ${ }^{\circledR}$ and UCS to the pattern of optical rotation of lactobionic acid found in the Merck Index. According to the Merck Index, the refractive index obtained by polarimetry for lactobionic acid was $[\alpha]_{\mathrm{D}} 20+22.6^{\circ}[20]$. As shown in Table 2, the optical rotation for the Zymomonas-produced lactobionic acid was $[\alpha]_{\mathrm{D}} 20+22.5^{\circ}$, which was similar to the value described in the Merck Index, demonstrating that the lactobionic acid produced by Zymomonas mobilis at UCS did not contain contaminants or isomeric/racemic mixtures.

By comparing these results to those for the lactobionic acid salt from Sigma ${ }^{\circledR}$, one can see that the optical deviation of the Sigma ${ }^{\mathbb{B}}$ sample increases by $17 \%$ when compared to the value from the Merck Index [18], which is probably due to the fact that the lactobionic salt from Sigma ${ }^{\circledR}$ was $97 \%$ pure.

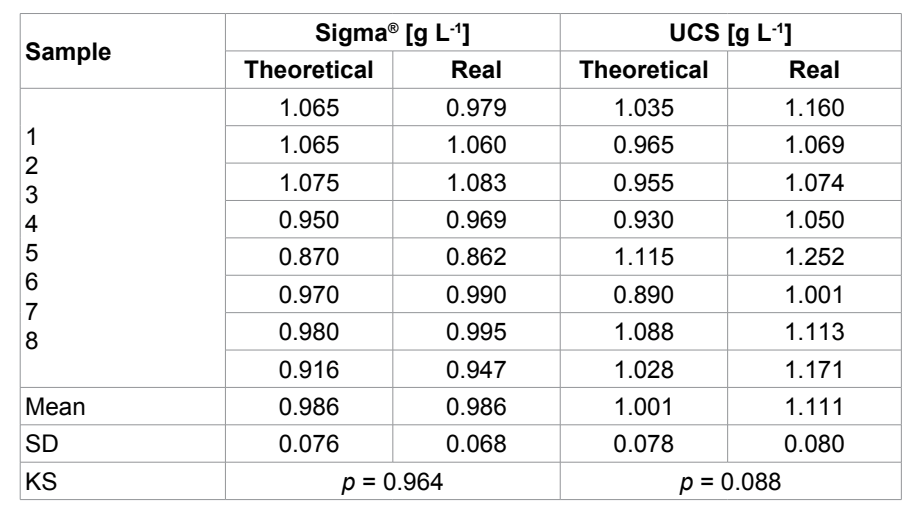

SD: Standard deviation. KS: Kolmogorov-Smirnov test

Table 1: Comparison of the theoretical and real purity values of lactobionic acid salts by high performance liquid chromatography (HPLC) analysis.

\begin{tabular}{|c|c|c|}
\hline Lactobionic acid & {$\left[\mathbf{\alpha}_{D}{ }^{20}\right.$} & $\%$ in relation to the Merck Index \\
\hline SIGMA $^{\circledR}$ & $+27.10^{\circ}$ & $17 \%$ \\
\hline UCS & $+22.50^{\circ}$ & $0 \%$ \\
\hline
\end{tabular}

Table 2: The refractive index of lactobionic acid samples obtained at the final time. 


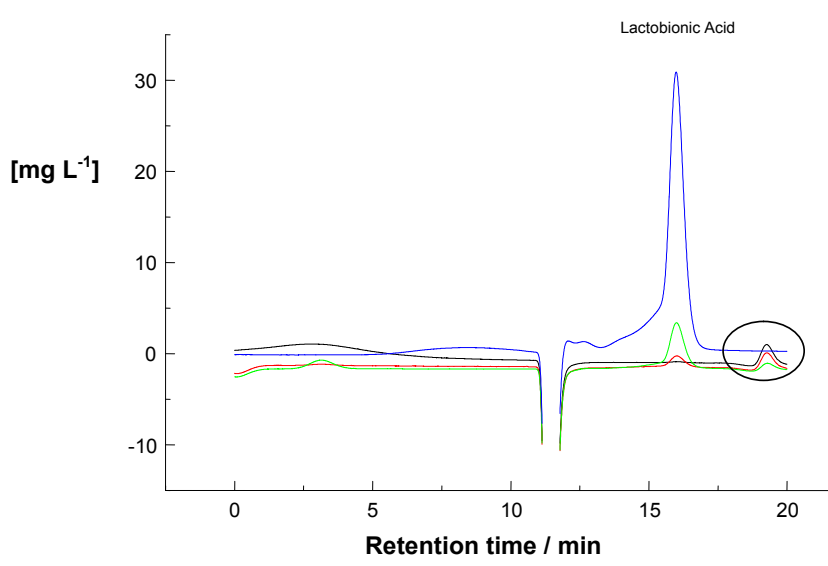

Figure 1: HPLC chromatograms for lactobionic acid calibration curve samples. Samples were a four dilution series of the standard lactobionic acid salt from Sigma®. A second peak, which was observed in the samples with low concentrations (below $10 \mathrm{mg} \mathrm{mL}^{-1}$ ), is highlighted in a circle.

\section{NMR spectroscopy of lactobionic acid}

In biotechnological processes, it is essential to confirm the molecular structure of an organic compound that is made in microorganisms. Nuclear magnetic resonance (NMR) spectroscopy aids in the determination of the chemical structure (i.e., to identify the carbon-hydrogen backbone) and in many cases can be used to determine the entire structure $[21,22]$.

Duss et al. demonstrated the importance of NMR spectroscopy in the structural elucidation of carbohydrates and their derivatives $[22,23]$. NMR spectroscopy in carbohydrate research continues to be one of the most important analytical techniques for the structural characterization of both synthetic and isolated samples.

In NMR spectroscopy, electrons are charged and can be in one of two spin states. Some nuclei also have spin states $(1 / 2$ or $-1 / 2)$, and this property allows them to be studied by NMR. Commonly studied nuclei include $\mathrm{H}_{1}, \mathrm{C}_{13}, \mathrm{~N}_{15}, \mathrm{P}_{31}$, and $\mathrm{F}_{19}$. Because hydrogen nuclei (protons) were the first nuclei studied by NMR, the designation " $\mathrm{H}$ NMR" refers to the nuclear magnetic resonance of hydrogen. In contrast, " ${ }^{13} \mathrm{C} \mathrm{NMR"}$ refers to the nuclear magnetic resonance of carbon 13. These charged nuclei turn to create a magnetic field, and when an external magnetic field is applied to the core rotating the sample, the sample tends to align itself to the spin state of the lowest energy or against the magnetic field (a spin state of higher energy, $\beta$ ) [24]. Each core is surrounded by a cloud of electrons in constant motion. Under the influence of the magnetic field, these electrons force themselves to move in a direction that oppose the exerted magnetic field. This movement has the effect of partially shielding the core from the full force of the external field. Therefore, if one wants to change the frequency or the field there must be resonance in the armored core [24].

The frequency offset, or chemical shift, in NMR depends on the chemical environment of the nucleus because this is the source of variations in the shielding effect. Measuring the chemical shift as a field, or frequency, is one reason for this variation in the field that is required for the applied field or frequency variation for the frequency standard that is defined and designated by $\delta$ in parts per million [24].

The energy difference between the high $(\beta)$ and low $(\alpha)$ spin states of $\beta$ (high energy) and $\alpha$ (low energy) depends on the strength of the applied magnetic field. The higher the exerted magnetic field is in which the core is exposed, the greater the energy difference between the spin states $\alpha$ and $\beta$ will be. With the magnets that are currently available, only a small amount of energy is required to excite the spin [25].

\begin{tabular}{|c|c|c|}
\hline \multirow{2}{*}{ Carbon } & \multicolumn{2}{|c|}{$\delta(\mathbf{p p m})$} \\
\hline C1 & Lactobionic acid & Lactone \\
\hline C1' & 178.69 & 173.56 \\
\hline C2 & 103.64 & 103.43 \\
\hline C2' & 71.88 & 71.83 \\
\hline C3 & 72.27 & 72.02 \\
\hline C3' & 71.28 & 71.48 \\
\hline C4 & 81.68 & 80.61 \\
\hline C4' & 72.85 & 72.92 \\
\hline C5 & 68.84 & 68.98 \\
\hline C5' & 71.66 & 70.74 \\
\hline C6 & 75.51 & 75.87 \\
\hline C6' & 62.09 & 61.51 \\
\hline
\end{tabular}

Table 3: ${ }^{13} \mathrm{C}-\mathrm{NMR}$ chemical shifts corresponding to lactobionic acid and lactone (Varian AS-400)<smiles>O=C(O)C(O)C(O)C(OC1O[C@H](CO)C(O)[C@H](O)C1O)C(O)CO</smiles>

Figure 2: The structure of lactobionic acid and its corresponding carbons [(2,3,5,6-tetrahydroxy-4-tetrahydro-3,4,5-trihydroxy-6-(hydroxymethyl)- $2 \mathrm{H}$ pyran-2-hyloxy) hexanoic acid]

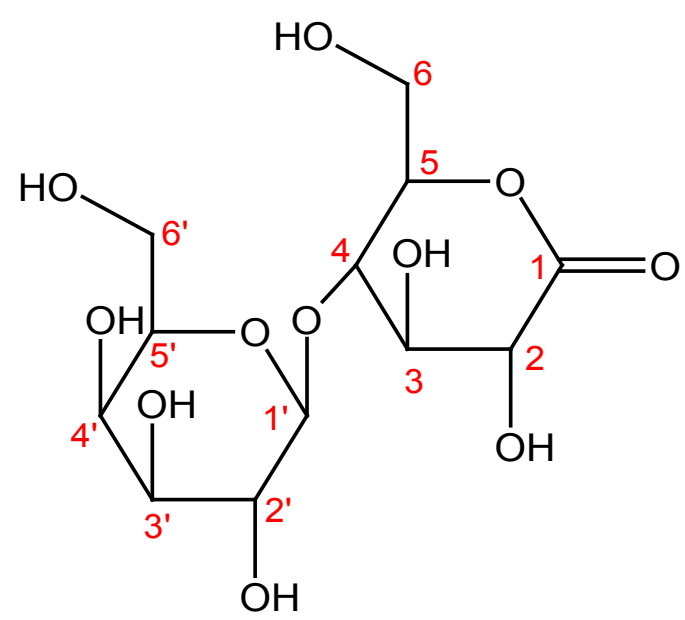

Figure 3: The structure of lactone and its corresponding carbons [(tetrahydroxy-3,4-dihydroxy-6(hydroxymethyl)-5-(tetrahydro-3,4,5-trihydroxy6(hydroxymethyl)-2H-pyran-2-yloxy)-2-one-pyran]. 
Citation: Valle TA, Ruzza ÂA, Mastroeni MF, Malvessi E, da Silveira MM, et al. (2013) Lactobionic Acid Produced by Zymomonas mobilis: Alternative to Prepare Targeted Nanoparticles. Pharmaceut Anal Acta 4: 220. doi:10.4172/2153-2435.1000220

Page 4 of 5

In the NMR spectrum of the lactobionic acid salt from Sigma ${ }^{\circledR}$, the chemical shift signal appears bent because there is a mixture of lactobionic acid (4-O- $\beta$-D-galactopyranosyl-d-gluconic acid) and lactone (4-O- $\beta$-D-galactopyranosyl-D-glucono-1,5-lactone). The structures of both these compounds are shown in Figures 2 and 3.

The chemical shift data that are presented in Table 3 were obtained from the ${ }^{13} \mathrm{C}$ NMR spectra $\left(\mathrm{D}_{2} \mathrm{O}, 400 \mathrm{MHz}, \mathrm{ppm}\right)$ of lactobionic acid and lactone with deuterated acetone $\left(\mathrm{C}_{3} \mathrm{D}_{6} \mathrm{O}\right)$ as the internal standard.

The chemical characterization of the Zymomonas-produced lactobionic acid and the standard Sigma ${ }^{\circledR}$ lactobionic acid salt allowed for a comparison of possible structural differences between the two samples. This characterization is important as structural abnormalities

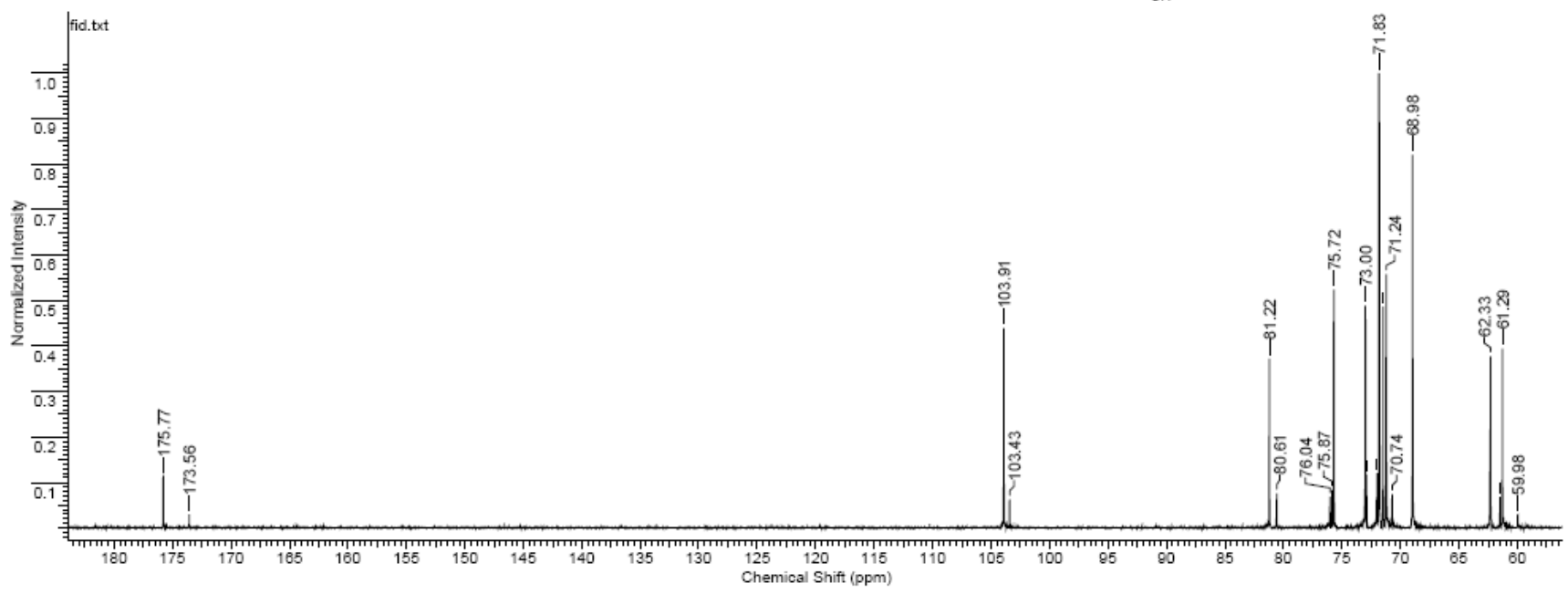

Figure 4: ${ }^{13} \mathrm{C}$ NMR spectrum of the lactobionic acid salt from Sigma ${ }^{\circledR}\left(\mathrm{D}_{2} \mathrm{O}, 400 \mathrm{MHz}, \mathrm{ppm}\right)$ with deuterated acetone $\left(\mathrm{C}_{3} \mathrm{D}_{6} \mathrm{O}\right)$ as the internal standard

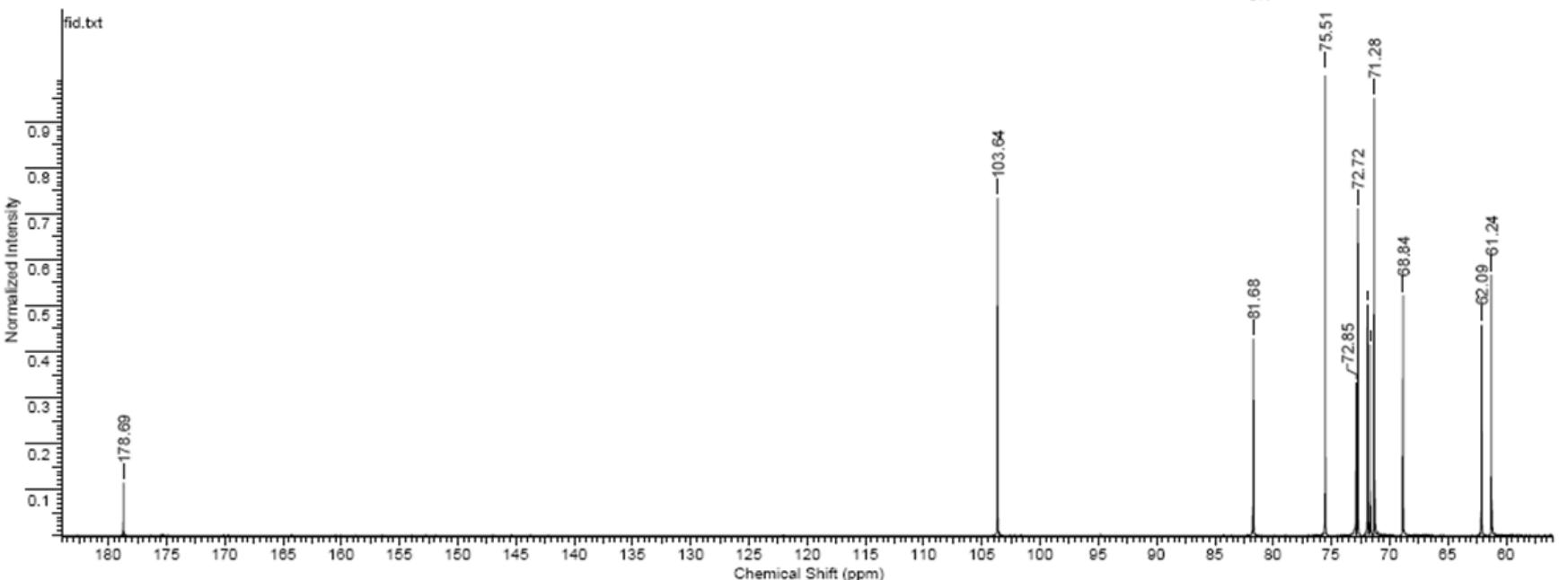

Figure $5-{ }^{13} \mathrm{C}$ NMR spectrum of lactobionic acid obtained by biotechnology processing at $U C S\left(D_{2} \mathrm{O}, 400 \mathrm{MHz}\right.$, ppm) with deuterated acetone $\left(\mathrm{C}_{3} \mathrm{D}_{6} \mathrm{O}\right)$ as the internal standard. 
Citation: Valle TA, Ruzza ÂA, Mastroeni MF, Malvessi E, da Silveira MM, et al. (2013) Lactobionic Acid Produced by Zymomonas mobilis: Alternative to Prepare Targeted Nanoparticles. Pharmaceut Anal Acta 4: 220. doi:10.4172/2153-2435.1000220

in lactobionic acid may cause problems when it is used for targeted delivery of drugs.

${ }^{1} \mathrm{H}-\left({ }^{13} \mathrm{C}\right)$ heteronuclear multiple-bond correlation spectroscopy (HMBC) allows for the detection of hydrogen across two or more bonds and can give very useful structural information. Using this technique, carbon-carbon correlations are obtained indirectly, and the correlations between hydrogen and the next tetra-substituted carbon can be detected

The interpretation of the $\mathrm{HMBC}$ experiment requires a degree of flexibility and can be difficult because you do not always find what you are seeking. However, HMBC spectroscopy can be used to determine whether lactobionic acids have the structures in the $\alpha$ or $\beta$ form and if they are pure compounds, racemic mixtures or other substances that have optical activity.

${ }^{13} \mathrm{C}$ NMR analysis of the lactobionic acid obtained from Zymomonas mobilis showed that it has greater symmetry when compared to the standard from Sigma ${ }^{\circledR}$. As shown in Figures 4 and 5, the NMR spectroscopy revealed variations in the spectrum of the lactobionic acid salt from Sigma ${ }^{\circledR}$. Minor variations were found in the NMR spectra of all samples. These variations were probably due to the presence of optical isomers, which was corroborated by the results from the polarimetry experiments.

Kokoh and Alonso-Vante observed the ${ }^{13} \mathrm{C}$ NMR spectrum of dry lactobionic acid without the supporting electrolyte and in $\mathrm{D}_{2} \mathrm{O}$, and the chemical shifts were given in ppm with chemical shifts of carbon from lactobionic acid showed signs of ring opening, while the carboxylic region showed signs of a closed lactone ring. Another discrepancy in the spectrum was attributed to the presence of lactone, which is usually in equilibrium with lactobionic acid in solution. Comparing our ${ }^{13} \mathrm{C}$ NMR results for the lactobionic acid made by Zymomonas mobilis with those in Kokoh and Alonso-Vante [25], it is evident that the sample is pure only if there are signs of ring opening and the absence of lactone. This result agrees with that of Toga et al. [26].

\section{Conclusions}

The lactobionic acid produced by Zymomonas mobilis is pure, has an open chain configuration, does not include any isomers (as observed using HPLC and NMR spectroscopy) and has great potential for use in a targeted drug delivery device. The quality of lactobionic acid that is produced via biotechnological processing at UCS is higher $(<100 \%)$ than that of the standard from SIGMA ${ }^{\circledR}(97 \%)$ used in the process of drug vectorization as described in the literature tetramethylsilane (TMS) as the internal standard [26].

\section{References}

1. Chin CM, Ferreira El (1999) O processo de latenciação no planejamento de fármacos. Química Nova 22: 75-84.

2. Vasir JK, Reddy MK, Labhasetwar VD (2005) Nanosystems in Drug Targeting: Opportunities and Challenges. Current Nanoscience 1: 47-64.

3. Torchilin VP (2000) Drug targeting. European Journal of Pharmaceutical Sciences 11: 81-91.

4. Wu F, Wuensch SA, Azadniv M, Ebrahimkhani MR, Crispe IN (2009) Galactosylated LDL nanoparticles: a novel targeting delivery system to deliver antigen to macrophages and enhance antigen specific $\mathrm{T}$ cell responses. Mol Pharm 6: 1506-1517.

5. Lin WJ, Chen TD, Liu CW (2009) Synthesis and characterization of lactobionic acid grafted pegylated chitosan and nanoparticle complex application. Polymer 50: 4166-4174.
6. Kamruzzaman Selim KM, Ha YS, Kim SJ, Chang Y, Kim TJ, et al. (2007) Surface modification of magnetite nanoparticles using lactobionic acid and their interaction with hepatocytes. Biomaterials 28: 710-716.

7. Kamruzzaman Selim KM, Xing ZC, Guo H, Kang IK (2009) Immobilization of lactobionic acid on the surface of cadmium sulfide nanoparticles and their interaction with hepatocytes. J Mater Sci Mater Med 20: 1945-1953.

8. Kim IS, Kim SH (2002) Development of a polymeric nanoparticulate drug delivery system. In vitro characterization of nanoparticles based on sugarcontaining conjugates. Int J Pharm 245: 67-73.

9. Kim IS, Kim SH (2003) Development of polymeric nanoparticulate drug delivery system: evaluation of nanoparticles based on biotinylated poly (ethylene glycol) with sugar moiety. Int J Pharm 257: 195-203.

10. Kim TH, Park IK, Nah JW, Choi YJ, Cho CS (2004) Galactosylated chitosan DNA nanoparticles prepared using water-soluble chitosan as gene carrier Biomaterials 25: 3783-3792.

11. Park EK, Lee SB, Lee YM (2005) Preparation and characterization of methoxy poly (ethylene glycol)/poly (epsilon-caprolactone) amphiphilic block copolymeric nanospheres for tumor-specific folate-mediated targeting of anticancer drugs. Biomaterials 26: 1053-1061.

12. Valle TA Ácido lactobiônico produzido por Zymomonas mobilis: uma alternativa para a vetorização de drogas. Masters dissertation in health and environment.

13. Silveira MM, Malvessi E, Carra S, Pasquali FC, Polidoro TA (2007) Processo de produção e recuperação de sorbitol e ácidos orgânicos ou seus sais preparação de elevada pureza isomérica de ácidos orgânicos ou seus sais. INPI patent by INBio / UCS under number 0700421-4.

14. Malvessi E, Carra S, Silveira MM, Ayub MAZ (2010) Effect of substrate concentration, $\mathrm{pH}$, and temperature on the activity of the complex glucosefructose oxidoreductase/glucono-delta-lactonase present in calcium alginateimmobilized Zymomonas mobilis cells. Biochemical Engineering Journal 51 : $1-6$.

15. Jonas R, Silveira MM (2004) Sorbitol can be produced not only chemically but also biotechnologically. Appl Biochem Biotechnol 118: 321-336.

16. Erzinger GS, Vitolo M (2006) Zymomonas mobilis as catalyst for the biotchnological production of sorbitol and gluconic acid. Appl Biochem Biotechnol 129: 787-794.

17. Pedruzzi I, Malvessi E, Mata VG, Silva EA, Silveira MM, et al. (2007) Quantification of lactobionic acid and sorbitol from enzymatic reaction of fructose and lactose by high-performance liquid chromatography. J Chromatogr A 1145: 128-132.

18. Pedruzzi I, da Silva EA, Rodrigues AE (2011) Production of lactobionic acid and sorbitol from lactose/fructose substrate using GFOR/GL enzymes from Zymomonas mobilis cells: a kinetic study Enzyme Microb Technol 49: 183-191.

19. The Merck Index, $14^{\circ}$ ed. Merck \& CO, INC. Whitehouse Station, NJ, USA 956, 2006.

20. de Lederkremer RM, Marino C (2003) Acids and other products of oxidation of sugars. Adv Carbohydr Chem Biochem 58: 199-306.

21. Bruice PY (2006) Organic Chemistry. Pearson Prentice Hall. (4 edn). Vol 1.

22. Duus J, Gotfredsen $\mathrm{CH}$, Bock K (2000) Carbohydrate structural determination by NMR spectroscopy: modern methods and limitations. Chem Rev 100: 45894614.

23. Ewing, Galen W. Métodos Instrumentais de Análise Química. Tradução Aurora Giora Albanese e Joaquim Teodoro de Souza Campos. Editora Edgard Blucher. São Paulo, 1990.

24. Frutos AA, Sala LF, Escandar GM, Peregrin JMS, Sierra MG (1997) Complex formation between D-lactobionate and bivalent metal ions. Studies in solution and in the solid state. Canadian Journal of Chemistry 75: 405-413.

25. Kokoh KB, Alonso-Vante N (2006) Electrocatalytic oxidation of lactose on gold nanoparticle modified carbon in carbonate buffer. Journal of Applied Electrochemistry 36: 147-151.

26. Taga T, Kuroda Y, Ohashi M (1978) Structures of Lanthanoid Complexes of Glyceric Acid, Gluconic Acid, and Lactobionic Acid from the LanthanoidInduced 1H NMR Shifts: pH Dependence of the Lanthanoid-Substrate. Bulletin of the Chemical Society of Japan 51: 2278-2282. 